\title{
Cloning and Sequencing of cDNA from Oryza sativa encoding a homolog to non-ATPase subunit, MBP1, of 26S Proteasome in Arabidopsis thaliana
}

\author{
Yuki YANAGAWA*, Tadamasa UEDA**, Kimiko YAMAMOTO***, Takuji SASAKI**, Keiji TANAKA ${ }^{\dagger}$, \\ Junji HASHIMOTO**, Takahide SATO*, and Hiroki NAKAGAWA*,+t
}

Received 25 March 1998; accepted 18 May 1998

In eukaryotes, the intracellular degradation of proteins is a precisely controlled process. This control is ensured partly by an enzyme system capable of selectively marking proteins intended for rapid intracellular degradation by the covalent attachment of ubiquitins, and partly by a multicomponent ATP-dependent protease, the $26 \mathrm{~S}$ proteasome which clusively degrades ubiquitinated proteins [1-5].

Target specificity within the ubiquitin pathway is determined by two recognition steps $[6,7]$. The first selects appropriate substrates for ubiquitination. The second step in defining the specificity of ubiquitin -dependent proteolysis involves the recognition of multiubiquitinated proteins by the $26 \mathrm{~S}$ proteasome. Substrate selection by the $26 \mathrm{~S}$ proteasome is presumably mediated by the interaction of specific components of the 19S/PA700 regulatory complex with multiubiquitinated proteins. Although little is known for this essential step, a subunit of the human 19S/ PA700 regulatory complex, designated S5a, that can bind ubiquitin-lysozyme conjugates in vitro was recently identified [6]. The corresponding gene was subsequently identified in Arabidopsis thaliana [7]. Sequence analysis revealed that homologs to this gene, designed AtMBP1 for $A$. thaliana multiubiquitin -binding protein, are present in a wide variety of other eukaryotes as well, including Saccharomyces cerevisiae, Drosophila melanogaster, Coenorhabditis elegans, rice and caster beans [7].

Multiubiquitin chain binding is one of the key functions of the $26 \mathrm{~S}$ proteasomal-selective degradation process. We tried to clone and analyze a full length cDNA encoding a subunit of proteasome, a homologous to $A$. thaliana MBP1, from rice (Oryza sativa L., cv. Nipponbare), which is a monocotyledonous plant.

\footnotetext{
* Department of Bioproduction Science, Faculty of Horticulture, Chiba University, 648, Matsudo, Chiba 271-8510, Japan

** National Institute of Agrobiological Resources, 2-1-2, Kannondai, Tsukuba, Ibaraki 305-8602, Japan

** Society for Techno-innovation of Agriculture, Forestry and Fisheries (STAFF) 446-1, Ippaizuka, Tsukuba, Ibaraki 305-0854, Japan

+ The Tokyo Metropolitan Institute of Medical Science, 3-10-13, Honkomagome, Bunkyo-ku, Tokyo 113-0021, Japan

${ }^{\dagger}$ To whom correspondence should be addressed

The nucleotide sequence data reported this paper will appear in the DDBJ, EMBL and GenBank nucleotide sequence databases under the following accession number AB010740.
}

Our large-scale sequencing of randomly chosen rice cDNAs has produced many cDNAs which exhibit significant sequence similarities to previously established sequences [8]. Among them, a cDNA clone from 8-day-old rice seedling mRNAs, OsS5a (Oryza sativa Subunit 5 a), exhibited strong homology to $A$. thaliana $M B P 1$.

It is likely that the cDNA insert represents the complete coding region of the gene. The clone contains an ORF from an ATG codon located at position 71 , until a stop codon at position 1279 , followed by a 256-bp $3^{\prime}$ untranslated region with a poly (A) tail.

The ORF encoded a protein of 402 amino acids. Using the Smith and Waterman homology search [9], significant homology was observed with potential products of ORFs from $A$. thaliana MBP1 (64.9\% identity) [7], human S5a (42.1\% identity) [10], $D$. melanogaster S5a (38.3\% identity) [11] (Fig. 1). This amino acid sequence had a highly conserved $\mathrm{N}-$ terminal region and had some characteristic motifs. We detected a nuclear localization signal (NLS) sequence, as well as $\alpha$-type proteasomal subunits [12]. Recentry it was shown that the highly conserved region (residue 213 to 242 ) with a GVDP motif and a repeated hydrophobic sequence (LALAL/ VorL) was necessary for the multiubiquitin chain binding $[13,14]$. This region in Rice OsS5a was also highly conserved, and thus it is likely that rice OsS5a functions also as a multiubiquitin binding protein. But rice OsS5a had a DVDP motif instead of the GVDP motif in this region although second GVDP motif (residue 366 to 369 ) which was not considered as a significant motif was well conserved [13]. It will be required to investigate the ability of multiubiquitin chain binding of rice OsS5a. Rice OsS5a possessed an alanine(A)-rich region starting at residue 200, similar to $A$. thaliana MBP1. It may be a characteristic of plants because neither human nor $D$. melanogaster had this region $[10,11]$. The $\mathrm{C}$-terminal region was more poorly conserved than the $\mathrm{N}-$ terminal region. But interestingly, it had a KEKElike motif in the $\mathrm{C}$-terminal region similar to human S5a [10] and the KK at the C-terminus was especially well conserved. These KEKE motifs are present in 


\begin{tabular}{|c|c|}
\hline $\begin{array}{l}\text { rice OsS5a } \\
\text { Arabidopsis } \\
\text { human S5a } \\
\text { Drosophila }\end{array}$ & $\begin{array}{l}s \text { MBP } \\
55 \mathrm{a}\end{array}$ \\
\hline \multicolumn{2}{|l|}{ Consensus } \\
\hline $\begin{array}{l}\text { rice OsS5a } \\
\text { Arabidopsis } \\
\text { human S5a } \\
\text { Drosophila }\end{array}$ & $\begin{array}{l}s \quad M B P 1 \\
\text { S5a }\end{array}$ \\
\hline \multicolumn{2}{|l|}{ Consensus } \\
\hline $\begin{array}{l}\text { rice 0sS5a } \\
\text { Arabidopsis } \\
\text { human S5a } \\
\text { Drosophila }\end{array}$ & $\begin{array}{l}s \quad \mathrm{MBP} 1 \\
\mathrm{~S} 5 \mathrm{a}\end{array}$ \\
\hline \multicolumn{2}{|l|}{ Consensus } \\
\hline $\begin{array}{l}\text { rice 0sS5a } \\
\text { Arabidopsis } \\
\text { human S5a } \\
\text { Drosophila }\end{array}$ & $\begin{array}{l}s \quad M B P 1 \\
\text { S5a }\end{array}$ \\
\hline \multicolumn{2}{|l|}{ Consensus } \\
\hline $\begin{array}{l}\text { rice 0sS5a } \\
\text { Arabidopsis } \\
\text { human S5a } \\
\text { Drosophila }\end{array}$ & $\begin{array}{l}s \quad \mathrm{MBP} 1 \\
55 \mathrm{a}\end{array}$ \\
\hline \multicolumn{2}{|l|}{ Consensus } \\
\hline $\begin{array}{l}\text { rice 0sS5a } \\
\text { Arabidopsis } \\
\text { human S5a } \\
\text { Drosophila }\end{array}$ & $\begin{array}{l}s \quad M B P 1 \\
S 5 a\end{array}$ \\
\hline \multicolumn{2}{|l|}{ Consensus } \\
\hline $\begin{array}{l}\text { rice 0sS5a } \\
\text { Arabidopsis } \\
\text { human S5a } \\
\text { Drosophila }\end{array}$ & $\begin{array}{l}s \quad \mathrm{MBP} 1 \\
\text { S5a }\end{array}$ \\
\hline \multicolumn{2}{|l|}{ Consensus } \\
\hline $\begin{array}{l}\text { rice 0sS5a } \\
\text { Arabidopsis } \\
\text { human S5a } \\
\text { Drosophila }\end{array}$ & $\begin{array}{l}s \text { MBP1 } \\
\text { S5a }\end{array}$ \\
\hline \multicolumn{2}{|l|}{ Consensus } \\
\hline $\begin{array}{l}\text { rice 0s\$5a } \\
\text { Arabidopsis } \\
\text { human S5a } \\
\text { Drosophila }\end{array}$ & $\begin{array}{l}s \quad \text { MBP1 } \\
\text { S5a }\end{array}$ \\
\hline Conse & \\
\hline
\end{tabular}

MVLEATMICI DNSEWMRNGD YSPSRFQAQA DAVNLICGAK TQSNPENTVG

$\ldots$.... . ICI ... EWM. ... YS. S. LOA. T EAV. LL. GA. TO .... T.

$\ldots$... S. . VCV . . EYM. . . FL. T. LQA. Q DAV. IV. HS. TR. ... . N.

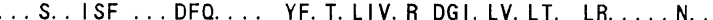

MVLE TMIC DNSE MRNGD Y P R QAO AVNL C K T SNPEN VG

VMTMAGKGVR VLVTPTSDLG KILACMHGLE VGAEANLAAA IQVAOLALKH

IL. MAGKGVR . . T. P. S. L. K. LACM. GLD VGGEINLTAA . OI. Q. A. .

LI. LA-NDCE .. T. L. P. T. R. LSKL. TVQ PKGKITFCTG . RV. H. A. .

LM. LS-NTVE .. A. L. S. A. R. FSKM. LVQ PKGEINLLTG . RI. H. V. .

T A V VL T TSD G IL MH E NL I A LALKH

RONKRQQQRI IAFIGSPVKY DKKVLETIGK KLKKNNVALD IVDFGETDDD

. N. NQRQ. . IV. A. . . IKY EKKA. EIVG. R. .. NS. SL. . VN. . EDDDE

.. G. NHKM. . I A. V. .. VED NEKD. VKLA. R. .. EK. NV. . IN. EEEVN

.G. NHKM. . VV. V. . I I NH EEGD. VKQA. R. . EK. NV. . VS. . DHGNN

$$
\text { K L } \underset{* * *}{K} \underset{* * *}{\text { LKK }} \mathrm{V} \text { D IV FGE }
$$

-KPEKLEALI SAVNSSDSSH IVHVPPGENA LSDVLISTPI FTGEEGGSGF EKPOKLEALL TAVNNNDG. I. H. .S. ANA.S. V. L. T. V FT. DE. ASGY TEKLTAFVNT LNGKDGTG. . L. T. . P. P-S. A. A. I. S. I LA. EG. -AML

NEILTAFINA LNGKDGTG. . L. S. . R. S-V . S. A. L. S. I IO. ED. MGGA SH $V$ VP G LSD L S PI GE G G

I AASAAAAAAT GAAGFEFDVD PNVDPELALA LRLSMEEERA ROEAIAKKAA \begin{tabular}{l|llll}
$\begin{array}{l}\text { AASAAAAAAT } \\
\text { VSAAAAAAAA }\end{array}$ & GAAGFEFDVD PNVDPELALA & LRLSMEEERA & ROEAIAKKAA \\
\hline
\end{tabular} GLGA- $\ldots$-SD. E. G. . . SA. .... . . V. . . Q. Q . . EEARR. A

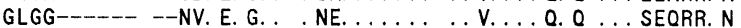

A - FEF VD PN DPELALA LR SMEE R RQE A AA

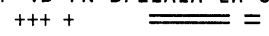

EESSGAENKD HASSSNADSV MAEAEPASNA ADDKKDOPKE DDDAOLLOQA DEAGOKDKDG DTASASOETV - - - - AR TTDKNAEPM- DEDSAL. DOA DEAGQKDKDG DTASASQETV -----AR TTDKNAEPM- DEDSAL. DQA AASA---AEA GIATTG---
PDGA---PPT GGDAGGGGGV SGSGPGNEES AGAENEA--- NTEEAM. ORA

$$
\checkmark \text { D D LL A }
$$

LAMSMEEGSS GAAAADAAMA EAAVDDODLA LALOMSVODA GGSSOSDM-S IAMSVGD--- ----VVMS EAADEDODL. L. L....MSGE ESSEATGAGN IS-OOEFGR- --- TGLPDL SSMTEEEQI. Y. M. . . LQGA ESGQAESADI IS-QOEFGR- - --TGLPDL SSMTEEEQI. Y. M. . . LQGA EFGQAESADI
LALSTETPE- ----DNLPDF ANMT. EEQI. F. M. . MQDA P-DDSVTQQA

K-_-_-- --_-_ VFEDRSFVTS ILNSLPGVDP NDPSVKDLLA

N--KRPKTDEANA PMDVDEDYSE VIGDPA. LQ. V. EN. ...... OSEAVRDAVG 378 III

- VDF $S$ L LPGVDP N V

400

SLHGQGEQ-E KKEDKSDKPE DEKK

PDESKRTE EEESSSKKGE DE.

ASOATKDG KKDKKEE--- - D.

NKDKDK-- ---KSDGKD SO. .

$S L$

KS

KK

Fig. 1 The alignment of the amino acid sequence of the rice OsS5a subunit with those of equivalent proteasome subunits of other species, Arabidopsis MBP1, human S5a, and Drosophila S5a subunits. The asterisk ( *) shows the nuclear localization signal (NLS). Box I indicates the alanine (A) rich region. A significant region for multiubiquitin chain binding was reported [13, 14]. Box II indicates the corresponding region in rice OsS5a. The crosses and double underlines indicate G(or D) VDP motifs and a hydrophobic region, respectively. Box III indicates the KEKE-like sequence. Dots (.) indicate identical amino acid residues to the corresponding rice sequence, and dashes $(-)$ indicate blanks introduced to achieve maximum similarity.

PA28a, a-type subunits of the 20S proteasome, nonATPase subunits of the 19S/PA700 complex, and other proteins such as chaperonins. Thus, these regions have been believed to be involved in the formation of protein complexes $[15,16]$. Amino acids of rice OsS5a was larger than its homologs of other species. A. thaliana MBP1, exhibited the higher homology with rice OsS5a, was 16 residues shorter than the rice OsS5a. Amino acid components of this product provided isoelectric point (pI) of about 4.2. It is likely that this pI value, like human S5a, was lower than those of other 19S/PA700 regulatory subunits of rice [17].

Genomic Sourthen hybridization under high-stringency conditions revealed that the gene for rice OsS5a as well as its homologs was a single copy (Fig. 2) [7, $10,11]$. This gene was deduced to have at least 1 intron, because EcoRI digestion caused the formation 


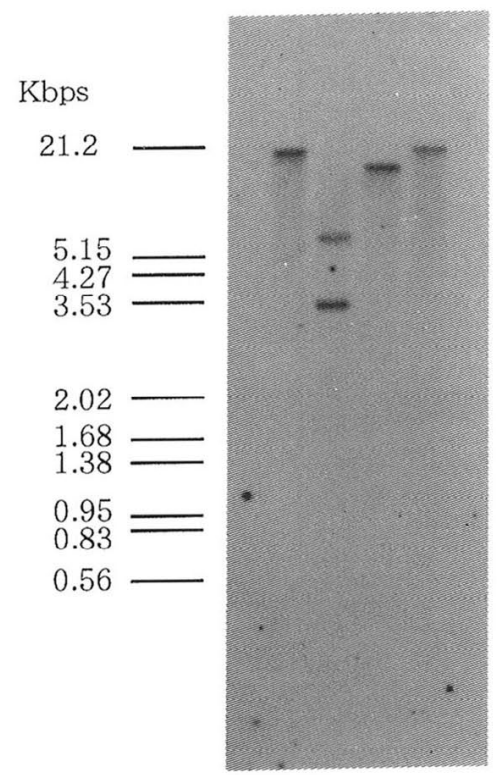

Fig. 2 Result of Southern blot analysis of rice genomic DNA probed with the full length OsS5a cDNA (about 1. $5 \mathrm{kbp}$ ). Genomic DNA was digested with the following restriction enzymes: Bgl II (lane 1), EcoRI (lane 2), Hind III (lane 3), Xba I (lane 4).

of 2 bands and cDNA for OsS5a has no EcoRI site. Under low-stringency conditions, several additional faint bands could be detected (data not shown). This result indicates that there are additional sequences similar to this gene in the rice genome.

RNA blot analysis revealed that its mRNA was expressed in both suspension cultures and rice seedlings (Fig. 3). The mRNA expression was especially high in suspension cultures that were proliferating rapidly. Ten-day-old seedlings are fully expanded cotyledons. Twenty-day-old seedlings develop true leaves and the cotyledons begin to turn yellow-green. In this 20-day-old seedlings, the mRNA was present at the lowest level. These results suggest that this subunit plays a role in cell proliferation or cell cycle progression.

\section{Acknowledgments}

This work was supported in part by a project grant from the "Research for the Future" program (JSPSRFTF 96L00604) of the Japan Society for the Promotion of Science, CREST (Core Research for Evolutional Science and Technology) of Japan Science and Technology Corporation (JST)) and a grant

\section{3}

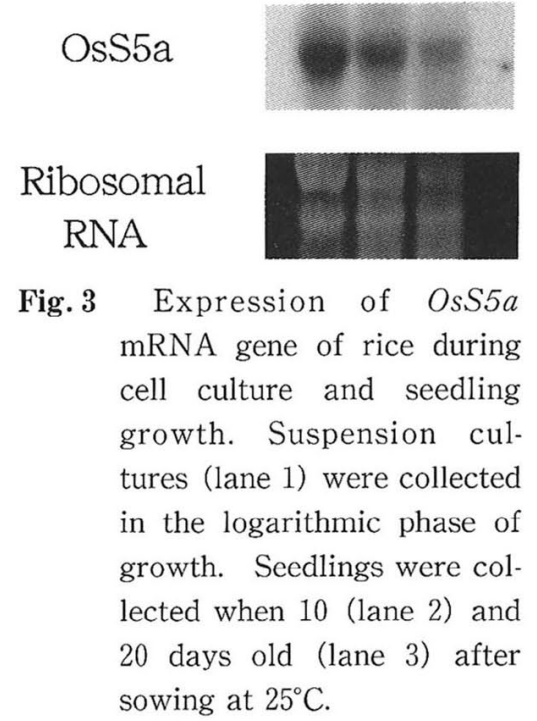

from "The Hamaguchi Foundation for the Advancement of Biochemistry" (to H.N.).

\section{References}

[1] Hershko, A., Ciechanover, A., 1992. Annu. Rev. Biochem., 61: 761-807.

[2] Johnson, E. S., Bartel, B., Seufert, W., Varshavsky, A., 1992. EMBO J., 11: 497-505.

[3] Rivett, A. J., 1993. Biochem. J., 291: 1-10.

[4] Ciechanover, A., 1994. Cell, 79: 13-21.

[5] Hayashi, S., Murakami, Y., 1995. Biochem. J., 306: $1-10$.

[6] Deveraux, Q., Ustrell, V., Pickart, C., Rechsteiner, M.,1994. J. Biol. Chem., 269: 7059-7061.

[7] Van Nocker, S.,Deveraux, Q., Rechsteiner, M., Vierstra, R. D., 1996. Proc. Natl. Acad. Sci. USA, 93: $856-860$.

[8] Sasaki, T., Song, J., Koga-Ban, Y., Matsui, E., Fang, F., Higo, H., Nagasaki, H., Hori, M., Miya, M., Murayama-Kayano, E., Takiguchi, T., Takasugi, A., Niki, T., Ishimaru, K., Ikeda, H., Yamamoto, Y., Mukai, Y., Ohta, I., Miyadera, N., Hvukkala, I., and Minobe, Y., 1994. Plant J., 6: 615-624.

[9] Smith, T.F. and Waterman, M., 1981. J. Mol. Biol., 147: 195-197.

[10] Ferrell, K., Deveraux., Q., van Nocker, S., Rechsteiner, M., 1996. FEBS Lett., 381: 143-148.

[11] Haracska, L., Unverdy, A., 1995. Eur. J. Biochem., 231: 720-725.

[12] Nederlof, P. M., Wang, H.-R., Baumeister, W., 1995. Proc. Natl. Acad. Sci. USA, 92: 1206012064.

[13] Fu, H., Sadis, S., Rubin, D. M., Glickman, M., van Nocker, S., Finley, D., Vierstra, R. D., 1998. J. Biol. Chem., 273: 1970-1981. 
[14] Haracska, L., Udvary, A., 1997. FEBS Lett., 412 : 331-336.

[15] Realini, C., Rogers, S. W., Rechsteiner, M., 1994. FEBS Lett., 348: 109-113.

[16] Realini, C., Dubiel, W., Pratt, G., Ferrell, K.,
Rechsteiner, M., 1994. J. Biol. Chem., 269: 20727 -20732 .

[17] Coux, O., Tanaka, K., Goldberg, A. L., 1996. Annu. Rev. Biochem., 65: 801-847. 